\title{
Reading Architecture: Explorative Text-ual Reception for Architectural Education
}

\author{
M. Mirza Y. Harahap ${ }^{1, *}$, Yandi Andri Yatmo ${ }^{1}$, Paramita Atmodiwirjo ${ }^{1}$ \\ ${ }^{1}$ Department of Architecture, Universitas Indonesia, Indonesia
}

\begin{abstract}
This paper discusses how reading is central to the architectural practice and how it carries an immense potential for design method, it is further argued that an act of reading is important to be introduced and learned in the architectural education institution within which students learn and develop various design methods. Accordingly, to this importance, this paper proposes a discussion toward various examinations of reading of various types of text. Stressing the discussion toward the conception of reception, interpretation, and representation, this paper aims to disclose the potential of the textual reading for design development by dismantling a range of exploratory reading acts, from literal act of reading to a developed act of reading, each of which positioned text as an event rather than an object. Each of the acts of reading ex Amined in the study takes a role as a process of creative analysis and interpretation which results in a representation of received knowledge.
\end{abstract}

Keywords: reading, text, method

\section{Introduction}

In architecture we discuss human, space and inhabitation. We study a broad range of discipline, from human behaviour to engineering. We design, learn how to make a good design and along the way, we also learn about design itself, continuously developing our effort to improve well-being. Within those processes, we perform careful yet deep consideration and calculation so that our design could successfully respond the uprising spatial issue(s). Consequently, the way we respond the issues arise in the environment is argued to be an important aspect to be paid attention to.

Understanding the world with every single phenomenon exist where there are continuous "Shifts in weather, changes in the behavior and needs of people" (Meagher, 2015, p. 160), is believed to be central and important in the overall design process. The needs to produce a flexible and adaptable design which responds to the ever-changing and shifting environment is then unavoidable (Meagher, 2015). Consequently this suggests the importance of reading the environment which would enable us to understand the environment itself as thorough as possible. Hence, the thorough understanding would enable one to come up with an innovation which responds to the uprising issue(s) thus offering the world as a better place to be inhabit.

Accordingly to this importance, this paper tries to explore the idea of reading as a means to understand the environment. Conducting an act of interpretation as the core of reading, the study particularly proposes reading as an explorative interpretational method for architectural design research and design development process.

\section{Reading in Architecture}

In architecture, to read means to uniquely understand and thoroughly grasp toward, but not limited to, certain phenomena exist in the environment. An ability to read is a quality an architect has to adequately possess. Particularly for an interior architect, reading, as Brooker \& Sally (2007) explicitly suggested in their book titled Basic Interior Architecture 01: Form + Structure, is especially important to perform an adaptation or remodelling toward an existing setting. Looking at this importance, we would like to invite the readers to take a heed toward what is reading.

It is believed that reading, as a distinctive manner of knowing and to achieve knowledge, to some extent could be described as an effort to construct particular meaning (Tierney \& Pearson, 1983; McGinley \& Tierney, 1988). Thus, reading —which particularly referred in this study, not as a literal act of reading such in reading a newspaper for example - can be considered as an act of extracting the meaning of a text.

However, the function of reading is not limited to an act of constructing the meaning of a text. Instead, this paper intends to explore how reading can be developed as an exploratory design method and be used in architectural design development. Considering that reading, as previously stated, is not limited to the literal act of reading and so is the text, this means reading possesses a wide range of possibilities to understand the

\footnotetext{
Corresponding author: mmyharahap@gmail.com
} 
environment with all of the phenomena occurred within. As reading is practically potential for architectural design, it is consequently then argued that reading needs our attention in the academic level, to be learnt and developed. McGinley \& Tierney (1988) argue that developing reading into a learning situation, or education in general, would particularly influence thinking and learning once reading is strategically applied in various forms. Particularly for architectural education, this implies that reading might be used as a way to understand environmental phenomena as a means to have a better understanding about the uprising spatial issues in the environment; as a design method.

Considering the above explanation, one may look at reading eminent with either hermeneutical or phenomenological conception. However we invite the reader to explore reading through the conception of reception instead. Proposing the reception as the corridor of the discussion, we try to explore reading as an exploratory act of interpretation which constitute critical analysis and creative thinking.

\section{Reception: Interpretation as a Means to Understand}

The discussion toward reading in this paper is proposed by looking at the idea of reception within which interpretation is performed, aiming an understanding toward particular text being read, indicating a process of acquiring knowledge. Stead \& Graduno (2013) argue that reception is distinct to the two conception which influenced it that are hermeneutics and phenomenology. It argues that the meaning of any particular phenomena which one tries to understand does not indwell within the text (Stead \& Graduno, 2013). It is rather "... focuses on practices: embodied, performed, and informed by a specific and unique set of circumstances. It demonstrates that the meaning of a text is always a dynamic negotiation, that texts and contexts can never really be distinguished as one can never know a text outside of its specific reception processes" (Stead \& Graduno, 2013, p. 269). This clearly informs that an act of operating the text in order to disclose the meaning lies within should be performed. This operating act is no other than reading itself. Stead and Graduno's argument also suggests two things: 1) In reception theory, reading and looking up at a particular meaning as a mean to understand is a dynamic process; and 2) Text is indistinguishable from context. The two hence indicate that the reception of knowledge from an understanding or extracted meaning about a particular text is a dynamic process of interpretation.

Extending the discussion, an interesting argument is suggested by Gough (2013) regarding the conception of reception is worth to be paid attention to. He stated that:

"The central tenet of any reception theory of architecture would have been the following call: collapse the subject-object divide. A literary text, it was said, is never-properly thought-an object, except as an after-effect. A literary text is rather an event-the event of reading that occurs in the interplay between the subject (the reader) and the object (the text)." (Gough, 2013, p. 280).

As argued by Gough (2013), reading text as an event rather than object becomes necessary since reading has a sense of give-and-take between us and what we are reading. This characteristics of reading, hence, needs to be our concern especially when reading is performed to understand the environment. This is also important especially when we consider how in architecture the relation between us -the inhabitant; the reader- and the space and everything exists within -the environment; the text- is extensively discussed.

Iser (2005) suggested that interpretation "... has always been: an act of translation" (Iser, 2000, p. 5), and we argue that it reflects how interpretation relates to representation. The translation here could be defined as an act of transposing the process of a thing into another form (Iser, 2000) which is conducted through representation. Here, interpretation and representation are seen as two aspects that affect one another. A form of interpretation, in a reading process, needs to be delivered in particular form of representation. On the other hand, each representation that is delivered in whatever form the reader chose, further performs the interpretation itself, leading to a potentially infinite process. Therefore, one must underline that the interpretation and representation are two inseparable aspects of reception. Schleiermacher in Iser (2000) further extended on how interpretation might be understand. He argued that interpretation is ".. a rigorous practice of discovering and elucidating the ramified conditionality of how understanding comes about" (Iser, 2000, p. 41). Thus, we can consider that in architecture, an act of interpretation, within which representation is involved, exists as a process of translating what exists in the environment, as the text, so that we can understand the environment.

Although reading process as a way to acquire knowledge is notable in many fields, from literature to art and architecture, what we really need to underline is that we have to embrace the transposition of its abstraction which allows us to assemble the very meaning of the text (Gough, 2013). And this could be accomplished by applying certain interpretation approach.

Schleiermacher in Iser (2000) explained that there are two methods of interpretation which are known: the divinatory method and the comparative method. The two methods are respectively defined as a method which "... seeks to gain an immediate comprehension of the author as an individual..." (Iser, 2000, p. 50) and “... proceeds by subsuming the author under a general type" (p. 50). The two methods will be discuss further in the following part of this paper. However, we need to note that these two interpretation methods are have a very close relationship between one another and that they are claimed to be the process that possibly ends up in the reception of knowledge (Iser, 2000). 


\section{The Two Interpretation Methods in Reading of Architecture}

Building an interpretation and delivering it through representation might be a challenge since it takes a reading which encounters a critical thinking and creativity in the process. Both divinatory and comparative methods require an effort of making each bears its own strength characterised from the representation itself. As previously described, the divinatory method incorporates an in-depth operation to understand the meaning while the comparative method is practically performed through an act of comparing.

In this part of the paper, we invite the reader to take a look at how reading through each interpretation methods might be performed. Each of the methods will be discussed separately. Then we will discuss how these two methods are related, by also referring to another example that combines these two methods.

\section{The Divinatory Method: An Exposition Toward Elliot the Elephant}

Conducting a reading which is performed through divinatory method might be a challenge since one needs to bravely take an in-depth translation toward what is offered in the text. Even reading a literal form of text, as what we will discuss, could be challenging yet compromising a distinct understanding of the discussed text. Elliot the Elephant: Loses his Voice, written by Christian Swift in 1998, might be just an ordinary children book. However, reading the content of this book as an event rather than merely just a book, an object, is another thing. Gough (2013) further suggested that "There is a meaning to the literary text, but this meaning is not (or not merely) passed across from the text to the reader, rather 'the meaning of the text is something that he has to assemble' (Gough, 2013, p. 280). Hence, in order to be able to assemble the meaning of a text, the challenge to overcome is how to see the text itself as an event which consists of what might construct and develop the meaning of the text itself. In the paper titled Text-Extracting Process: A Method in Developing a Story, Harahap \& Yatmo (2014) comprehensively explore the process of understanding how the content of the book develop its story. Through an extraction process, Harahap \& Yatmo attempted to explain how a literal text builds its story through the composition of what constructed a narrative text, which are the settings and the plot, and use the extraction for design purpose.

Reading the book seems reception of preliminary understanding that the book has certain aspects which could be used to further understand what is hidden beneath what is shown on the surface of the book. Settings and plot are firstly operated then the connectivity to one another is developed, which in the process is interpreted and delivered into certain form of representation.

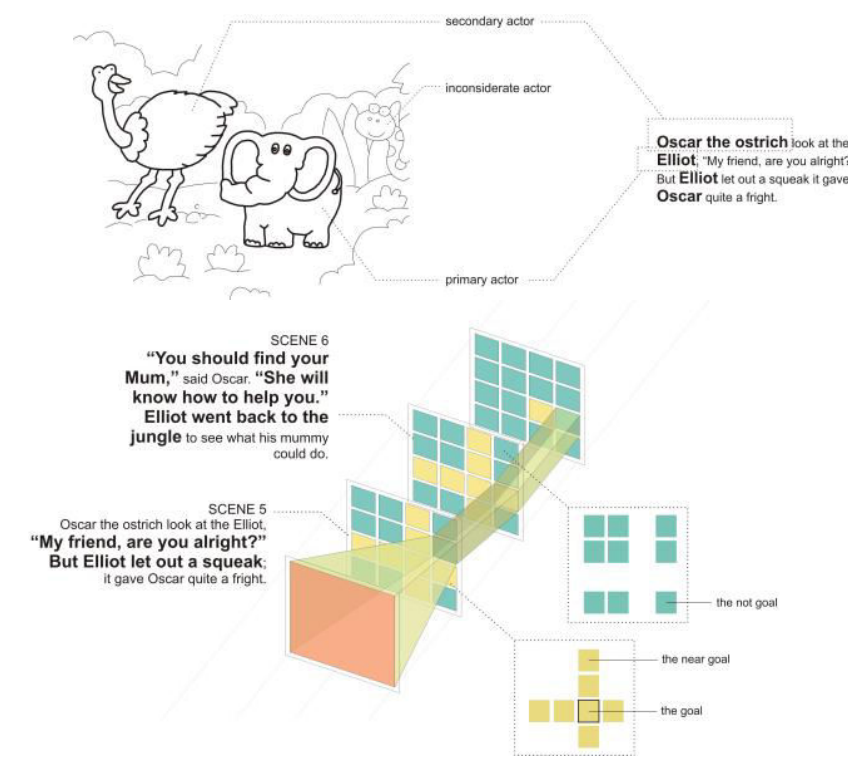

Fig. 1. The Operation of Settings. Source: Harahap \& Yatmo, 2014.

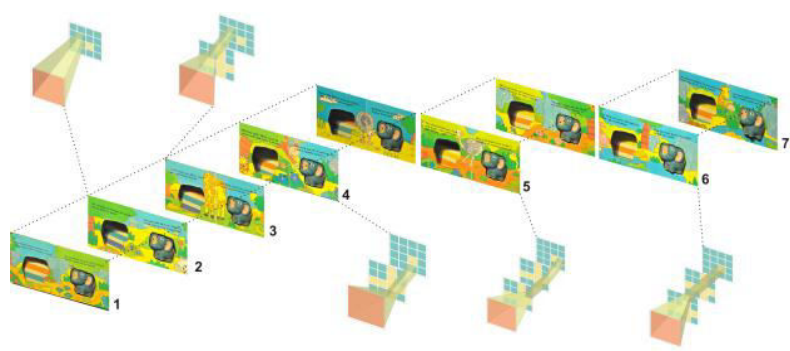

Fig. 2. The Operation of Settings. Source: Harahap \& Yatmo, 2014.

Figure 1 shows how this operation was conducted. Diagrams were used as the media to deliver the representation of the interpretation toward the setting. We suggest that it is a part of the reading itself, the extracting process. The diagrammatical representation performed particularly gives a chance to deeply interpret to what is exposed from the book and at the same time opens a possibility to make further interpretation. This is only possible as the authors deliver their interpretation into a developable and transformable diagram which respond to their needs on extracting the settings and plot, hence an understanding of the book is partly acquired. Overall, the process indicates a creative and critical thinking, a compromising preliminary act of reading of the setting.

What had been done as shown in Figure 1 was then applied to the whole pages of the book, resulting in a diagram as shown in Figure 2. This diagram particularly shows us how the interpretation which has been previously performed is conducted for other parts of the book. This is would then help the overall understanding of the book.

As an example of reading of which a divinatory approach for interpretation is applied, we argue that Harahap \& Yatmo (2014) has attempted to conduct a reading which ought to be an act of understanding text as 
event rather than object although the book is in a form of literal text.

\section{The Comparative Method: The Melting Layers Project}

The second interpretation method to be discussed in this paper offers a different approach which is conducted through a different representation yet a unique, if not even, quality of understanding. The discussion is conducted toward a set of text that appears as frozen liquids. However, this project is alike with how the previous interpretation method respond to the text, which is by not seeing the text as what it appears, the frozen liquids, but as an event of melting process instead.

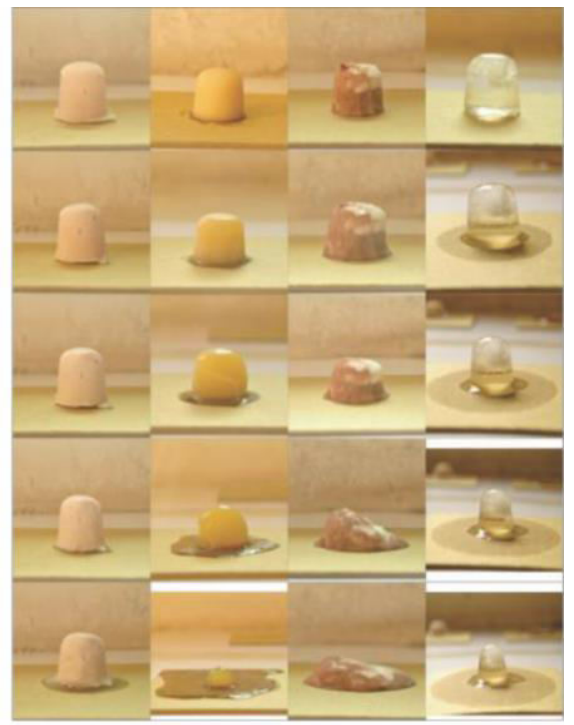

Fig. 3. Data of Melting Frozen Liquids. Source: Harahap, 2012.

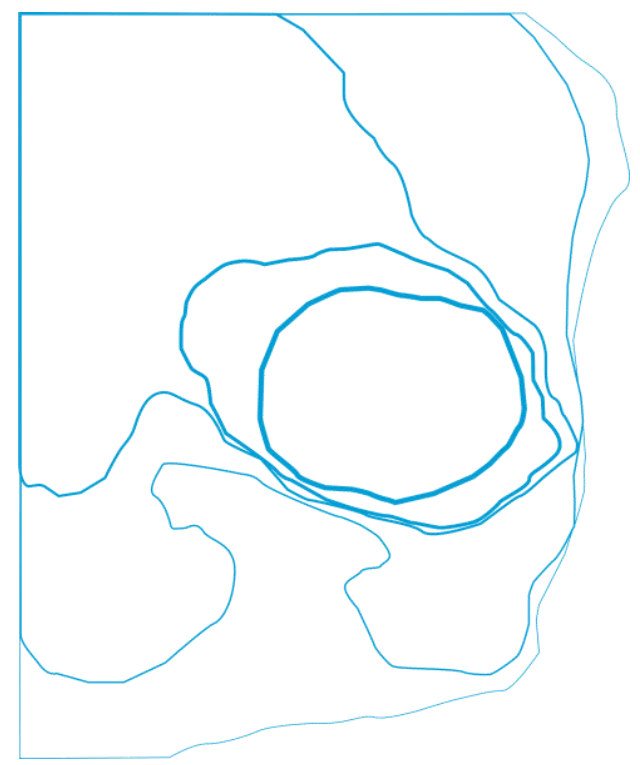

Fig. 4. Representation of the melting process which covers the two explored aspects.

Source: Harahap, 2015, development from Harahap, 2012.
As the name of the method suggests, the interpretation process to understand how the frozen liquids were melting is conducted by comparing the melting process from one liquid to another. Each melting process firstly went through an interpretation and delivered into certain representation. The Melting Layers project (see Figure 3), as explained by Harahap (2012) in the article which titled after the project, was done to explore how the frozen liquids melt by looking at three aspects: the dispersion, the shifting and the shrinkage of the melting frozen liquids. These three aspects are represented in the form of diagram. Basically, the reading conducted here is by interpreting and tracing the three mentioned aspects of a frozen liquid into a twodimensional diagram, although in this paper, only two are discussed (dispersion and shifting position) out of three aspects as there is a limitation to the access of the data.

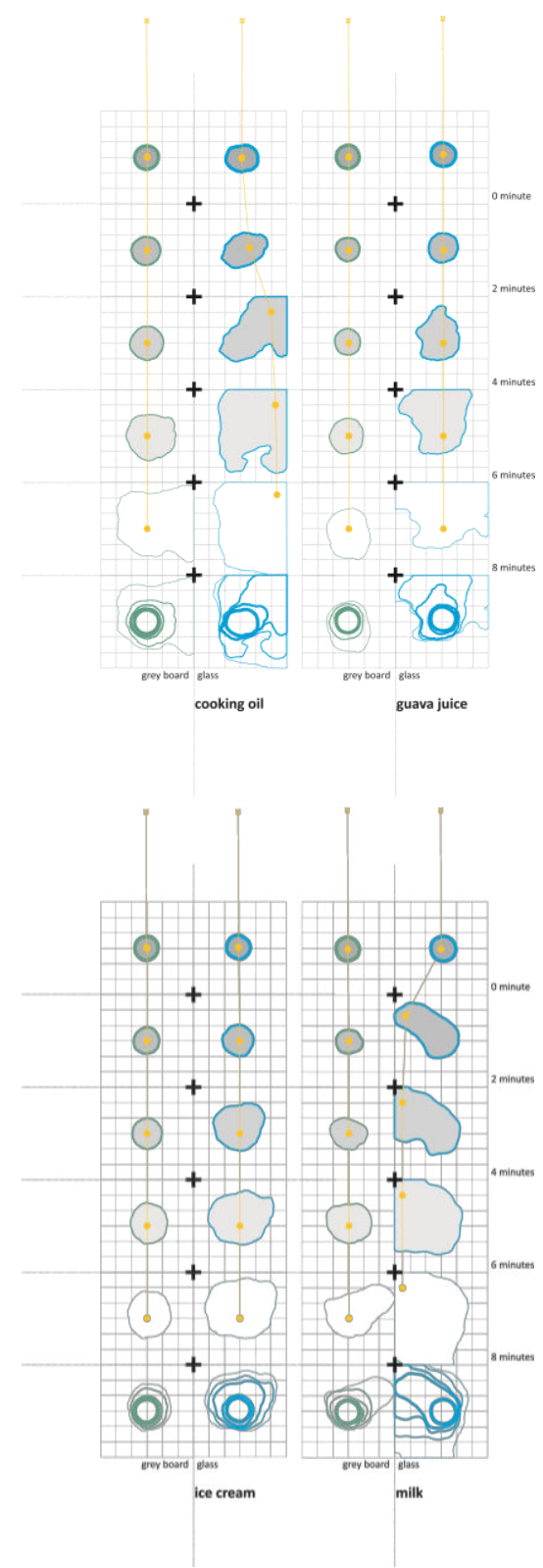

Fig. 5. Data of Melting Frozen Liquids. Source: Harahap, 2015, development from Harahap, 2012. 
The reception resulted from the observing of the melting process shown in Figure 3 determines the further interpretation and representation act. Particularly in this project, Harahap (2012) seems to look at the strong effect of time in the overall process, hence develop a form of representation which is correlated with how the data is recorded in a timely manner. Figure 4 shows the first stage of the diagrammatical representation which is more literal compared to the representation diagram of the first stage on reading Elliot the Elephant: Loses His Voice. The diagram shows the set of data of the melting liquid in a timely manner, performs the sequence of the melting process and, with the help of the additional grid, indicates how the two observed aspects are occurred.

This is then followed by applying the tracing process to the other frozen liquids as shown in Figure 5. From Figure 5, we can see that once the representation is applied to all of the frozen liquids, the comparison revealed the differences on how each of the melting processes occur. Moreover, the comparison also gives us an information toward how each frozen liquid is distinct to one another on how they melt, how their condition changes over time and how they later construct the understanding about the melting process. Moreover, the diagram represents the details of two out of the three explored aspects of the melting liquids which are the traceable changes of position and the measurable dispersion occur during the melting process. Accordingly to those explored aspects, thus through the conducted reading, Harahap (2012) then acquired a specific understanding toward melting process itself.

\section{The Combination of The Two Interpretation Methods for Reading a Rather Complex Text}

A reading process demonstrated by Atmodiwirjo et al. (2015) in the paper titled Dwelling Spatial Arrangement, Active Body Movement and Health, proposes a further approach to how one could interpret a text. This example demonstrated how a reading is conducted toward a more complex text; compared to the two examples which have been discussed previously. From their reading, we find a sense of combination of the two interpretation methods, each of which of course, for a specific purpose yet in the end of the reading process. Through this combination they could then acquire a whole understanding toward what they wanted to disclose.

Exploring the hodological space conception through an in-depth and comparative operation of particular dwelling context, they are able to pull out a rather important proposition for both architectural knowledge and for the importance of architectural design development as their proposition could be used for design justification as well.
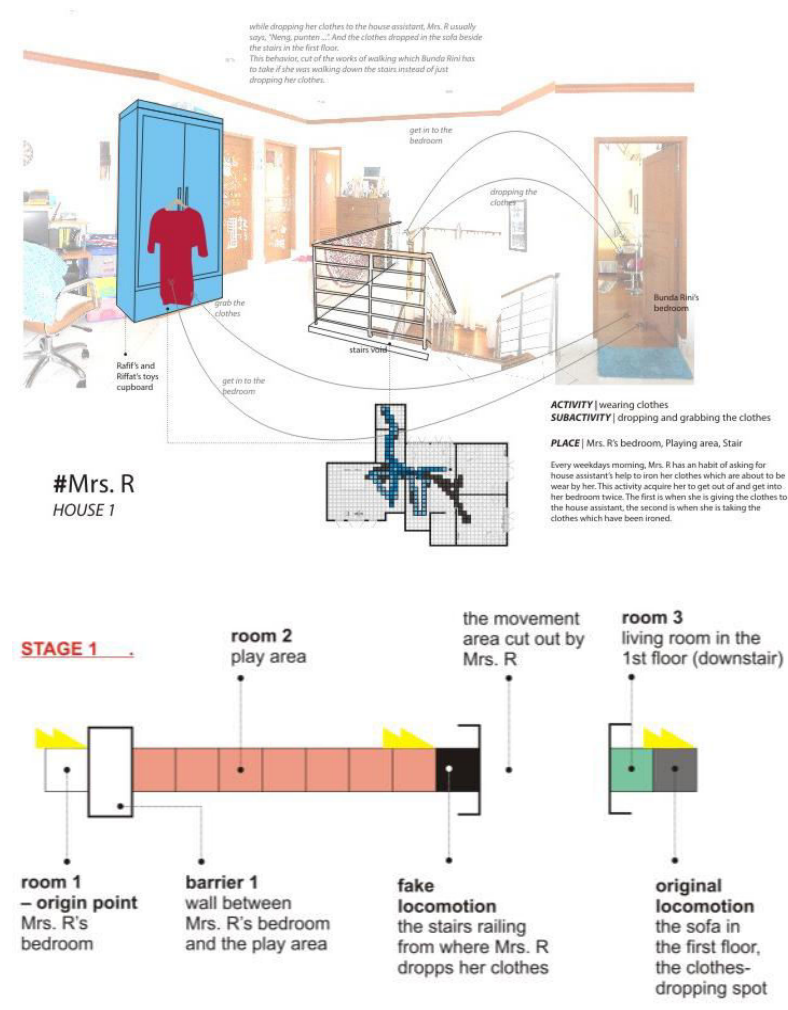

Fig. 6. Reading Dwelling Performed.

Source: Atmodiwirjo et al, 2015.

This example specifically indicates that reading is indeed could be used for architectural design importance, both theoretically and practically. It also indicates that reading is applicable even to a complex text. As long as a process of interpretation and representation is continuously and systematically conducted, we could understand and acquire knowledge from any kind of text. Up to this point, what we must further address is how far we can develop and apply the practice of reading in the academic environment. The three discussed examples clearly show how reading would be potential to be developed as a design method, yet, there is a challenge of how much we would concern ourselves with this potential? Architect, as well as interior architect and other design professions, does need reading to understand the uprising spatial issues, but learning and get used to reading is another thing. It is rather important to see reading as a necessary knowledge, especially in architectural education within which we try to understand human, inhabitation and space as what construct the world. Yet, we still rarely see the practice of reading is specifically cultivated among the students in architectural education institutions.

\section{Reading for Architectural Design Method}

As previously discussed, the first two project examples demonstrate how the two interpretation methods could be conducted and inform us three things: First, reading may or may not include a literal act of translation with no regard to when it is conducted in the overall process 
of interpretation and representation as it depends on how one chooses to interpret what he/she has been preliminary received; Second, as argued by Schleiermacher in Iser (2000) which suggested that there is a sense of correlation between the first two interpretation methods, the two discussed reading examples are each positioned the in-depth and the comparative approaches support each other in the overall effort to understand the text, although one will more likely to emerge stronger than the other in a single reading act. Consequently, the two interpretation methods show the very potential of reading itself.

Third, the last example which conducts how the two interpretation methods could be used simultaneously in one process of reading further expand what we have learn from the first two projects. The literal translation which may be performed as part of the overall interpretation could be repressed on its effect, thus, reducing the possibility of conducting an interpretation which could only acquire an outer understanding rather than an in-depth one. However the two methods hold their own strength for the interpretation importance, consciously combining them in a whole reading process is proven useful when the text appears in a more complex state.

These findings then further emphasise Iser's suggestion that "The two forces that Schleiermacher perceived in interpretation and in human thinking generally are versions of two processes that are indeed comprised in every realm of thought that can lay claim to knowledge" (Iser, 2000, p. 50). As reading is performed as an effort to understand a particular thing through a process of critical interpretation whether it is through divinatory method, comparative method or the combination of the two methods, the result apparently is full of potential with various, if not unlimited, ways to receive and claim knowledge. Related to architectural practice where an understanding toward any phenomena occur in the environment is necessary so that one could make a suitable respond to the uprising issue(s), the potential particularly indicates that reading might be useful to be developed to support, if not as, architectural design method as well.

Looking at reading as a method, the authors argue that it could be develop in the design process for various usage. The result of the reading conducted by Harahap \& Yatmo (2014) as discussed earlier, were used to construct the programming idea of the architectural design proposed in their project. The result of reading in the research project conducted by Paramita et al. (2015), as previously discussed, could be used as a suggestion for design development. The two results also suggest the importance of design research which broadly learned in the architectural education institutions.

\section{Conclusion}

Reading, based on our discussion through various examples, is considerably and arguably potential to achieve particular understanding and claim certain knowledge on something. The variety of text which exists in the world, through a process of interpretation which incorporates representation within, gives us a chance and possibility to receive as much knowledge as we can. The two methods, that are the divinatory and comparative method, are proven effective for reading purpose. While each of those methods is exceptionally distinct in their own way, yet the two actually are interconnected one another in one process of reading.

All of the discussions toward reading itself suggest an urge to further explore reading, particularly for architectural education. Its flexibility and possibility make reading a rather important discourse to be developed. As the urge to deeply understand context so that we could have a better proposition to what kind of response we need to design to tackle the uprising spatial issues are getting significant, the urge to learn how to read is getting significant as well. Specifically for this matter, we argue that reading, in whatever form it is delivered in an architectural education, must always in an open state, meaning, that as reading is flexible and highly subjective in its nature and text is always changes over time, thus reading will continuously develop.

Looking at reading as a method also suggests that reading is essential for architectural design education. Reading generally enables us to understand the environment, thus, gives us a better chance for responding the arising issues. Reading as method is also specifically useful as a part of design research, covering both design development importance and the architectural research.

\section{References}

Atmodiwirjo, P., Harahap, M. M., \& Yatmo, Y. A. (2015). Dwelling Spatial Arrangement, Active Body Movement and Health. i-dwell International Conference on Dwelling Form 2015, (pp. 29-44). Mataram.

Brooker, G., \& Stone, S. (2007). Basics Interior Architecture 01: Form and Structure: The Organisation of Interior Space. Lausanne: Bloomsbury Publishing PLC.

Gough, T. (2013). Reception Theory of Architecture: Its Pre-History and Afterlife. Architectural Theory Review, 18(3), 279-292.

Harahap, M. M. (2012). The Melting Layers. arsitektur.net Jurnal Teori dan Desain Arsitektur, 6(2), 34-37.

Harahap, M. M., \& Yatmo, A. Y. (2014). TextExtracting Process: A Method in Developing A Story. [in] arch International Conference 2014 (pp. 139-148). Depok: Department of Architecture, Faculty of Engineering, Universitas Indonesia.

Iser, W. (2000). The range of interpretation. New York: Columbia University Press.

McGinley, W., \& Tierney, R. J. (1988). Reading and Writing as Ways of Knowing. Champaign: Bolt Beranek and Newman Inc. 
Meagher, M. (2015). Designing for change: The poetic potential of responsive architecture. Frontiers of Architectural Research(4), 159-165.

Stead, N., \& Garduno, F. C. (2013). Architecture and "The Act of Receiving, or the Fact of Being Received": Introduction to a Special Issue on Reception. Architectural Theory Review, 18(3), 267271.

Tierney, R. J., \& Pearson, P. D. (1983). Toward A Composing Model of Reading. Champaign: Bolt Beranek and Newman Inc. 